\title{
Meta-analysis of the diagnostic performance of stress perfusion cardiovascular magnetic resonance for detection of coronary artery disease
}

\author{
Michèle Hamon*1,2, Georges Fau', Guillaume Née33, Javed Ehtisham4, Rémy Morello5 and Martial Hamon4,6
}

\begin{abstract}
Aim: Evaluation of the diagnostic accuracy of stress perfusion cardiovascular magnetic resonance for the diagnosis of significant obstructive coronary artery disease (CAD) through meta-analysis of the available data.

Methodology: Original articles in any language published before July 2009 were selected from available databases (MEDLINE, Cochrane Library and BioMedCentral) using the combined search terms of magnetic resonance, perfusion, and coronary angiography; with the exploded term coronary artery disease. Statistical analysis was only performed on studies that: (1) used a [greater than or equal to] 1.5 Tesla MR scanner; (2) employed invasive coronary angiography as the reference standard for diagnosing significant obstructive CAD, defined as a [greater than or equal to] 50\% diameter stenosis; and (3) provided sufficient data to permit analysis.

Results: From the 263 citations identified, 55 relevant original articles were selected. Only 35 fulfilled all of the inclusion criteria, and of these 26 presented data on patient-based analysis. The overall patient-based analysis demonstrated a sensitivity of $89 \%$ (95\% Cl: 88-91\%), and a specificity of $80 \%$ (95\% Cl: 78-83\%). Adenosine stress perfusion CMR had better sensitivity than with dipyridamole $(90 \%(88-92 \%)$ versus $86 \%(80-90 \%), \mathrm{P}=0.022)$, and a tendency to a better specificity (81\% (78-84\%) versus 77\% (71-82\%), $\mathrm{P}=0.065)$.
\end{abstract}

Conclusion: Stress perfusion CMR is highly sensitive for detection of CAD but its specificity remains moderate.

\section{Introduction}

Perfusion cardiovascular magnetic resonance (CMR) is an emerging technique for the detection of coronary artery disease (CAD). The technique is attractive because of its non-invasive nature and safe characteristics, and might potentially play a major role in future diagnosis and risk stratification guidelines for patients with suspected CAD. Several small studies have evaluated the diagnostic performance of stress perfusion CMR and some of those have been included in a previous meta-analysis [1]. In the current study we provide a comprehensive and contemporary meta-analysis of its diagnostic accuracy compared with an invasive coronary angiography (CA) used as a reference standard.

\footnotetext{
*Correspondence: hamon-mi@chu-caen.fr

1 Department of Radiology, University Hospital of Caen, France Full list of author information is available at the end of the article
}

\section{Methods \\ Search strategy}

Using the combined medical subject headings (MeSH) of magnetic resonance, perfusion, and coronary angiography, with the exploded terms coronary artery disease; the MEDLINE, Cochrane Library and BioMedCentral databases were searched independently by two investigators $(\mathrm{MH}, \mathrm{GF})$ for all publications, in any language, before July 2009. In addition, the published reference lists of these articles were systematically searched.

\section{Study eligibility}

The search results were collated by the same two investigators $(\mathrm{MH}, \mathrm{GF})$, and duplicate or overlapping papers removed. Studies were eligible if: [1] stress perfusion CMR was used as a diagnostic test for significant obstructive CAD; [2] conventional invasive CA was used as the reference standard for diagnosing significant obstructive $\mathrm{CAD}$, defined as a $\geq 50 \%$ diameter stenosis; and [3] the absolute numbers of true positive (TP), false positive 
(FP), true negative (TN), and false negative (FN) were reported, or could be derived. Studies were excluded if they were performed with a 0.5 or 1 Tesla MR scanner, if they included less than 10 patients, and if only abstracts from scientific meetings were published as the data provided may either be not sufficiently detailed or finalized. Any disagreements on eligibility were resolved by discussion and consensus between the two investigators.

\section{Data extraction and quality assessment}

Data extraction was performed independently by the two investigators $(\mathrm{MH}, \mathrm{GF})$ for each study. The following fields were recorded: study population size; gender distribution; mean age and standard deviation; number of patients with documented CAD; prevalence of CAD; relative timing of the two imaging procedures; the degree of blinding in interpretation of test results (both to the patient's clinical context and the results of the other imaging modality); type and brand of MR machine used; the type of perfusion stressor (adenosine, nicorandil, dipyridamole), and the number of side effects; the dose and injection rate of Gadolinium administrated; and the modality of MR image analysis (visual, or semi-quantitative). Any discrepancies were resolved by discussion and consensus between the two investigators. Where available, data was recorded separately at the level of coronary territories and coronary arteries. The study quality conformed to the Quality Assessment of Studies of Diagnostic Accuracy included in Systematic Reviews guidelines [2]. In one study, for which patients were evaluated both with 1.5 and 3T CMR, we used $1.5 \mathrm{~T}$ data in the metaanalysis. For the studies where analysis was performed with both $50 \%$ and $70 \%$ coronary stenosis definitions, we included results with the $70 \%$ definition in the pooled reported sensitivity and specificity.

\section{Data synthesis and statistical analysis}

Data analysis was performed at the level of the patient, the coronary territory and the coronary artery. Sensitivity and specificity were calculated using the TP, TN, FP, and FN rates $[3,4]$. From these were calculated the likelihood ratios, which express how much the odds of significant obstructive CAD change in the presence of either an abnormal stress perfusion CMR (positive likelihood ratio: PLR = sensitivity/(1- specificity)), or a normal stress perfusion CMR (negative likelihood ratio: NLR = (1- sensitivity)/specificity). Finally, the ratio of the PLR to the NLR was used to calculate the diagnostic odds ratio (DOR), which estimates how much greater the odds of having significant obstructive CAD are for patients with a positive test result compared with a negative one.

All these measures of diagnostic accuracy were calculated for each individual study and reported as point estimates with 95\% confidence intervals. They were then combined using a random-effects model and each point estimate weighted by the inverse of the sum of its variance and the between-study variance. We also assessed between-study statistical heterogeneity using the Cochran Q chi-square tests (cut off for statistical significance $P \leq .10$ ). Since diagnostic parameters are, by definition, interdependent, independent weighting may sometimes give spurious results and provide biased estimates; to overcome the interdependence problem, we computed the weighted symmetric summary receiver operating characteristic curve, with pertinent areas under the curve, using the Moses-Shapiro-Littenberg method [5-7]. All statistical calculations were performed with SPSS 14.0 (SPSS, Chicago, IL) and Meta-DiSc [8], and significance testing was at the two-tailed 0.05 level [9].

\section{Results}

Database and literature searches retrieved 263 citations, amongst which 55 relevant publications were identified (Figure 1). Further scrutiny led 20 papers to be rejected either because of overlapping data, or exclusion criteria were met (employed 0.5 or $1 \mathrm{~T} \mathrm{CMR}$, or inclusion criteria were absent (impossible to find or calculate absolute figures from presented data). Therefore, 35 studies were finally included in the meta-analysis [10-44], all of which had been published between 2000 and 2009. Study and population characteristics are summarized in Table 1, and the results of the pooled analyses are summarized in Table 2. Dose of contrast Gadolinium administrated range from 0.025 to $0.15 \mathrm{mmol} / \mathrm{kg}$, with an injection rate varying from 3 to $10 \mathrm{~mL} / \mathrm{s}$. Quality assessments for all included studies are shown in Table 3. The 35 papers eligible for the analyses comprised 2,456 patients, and of the 2,154 patients for whom gender and the age were speci-

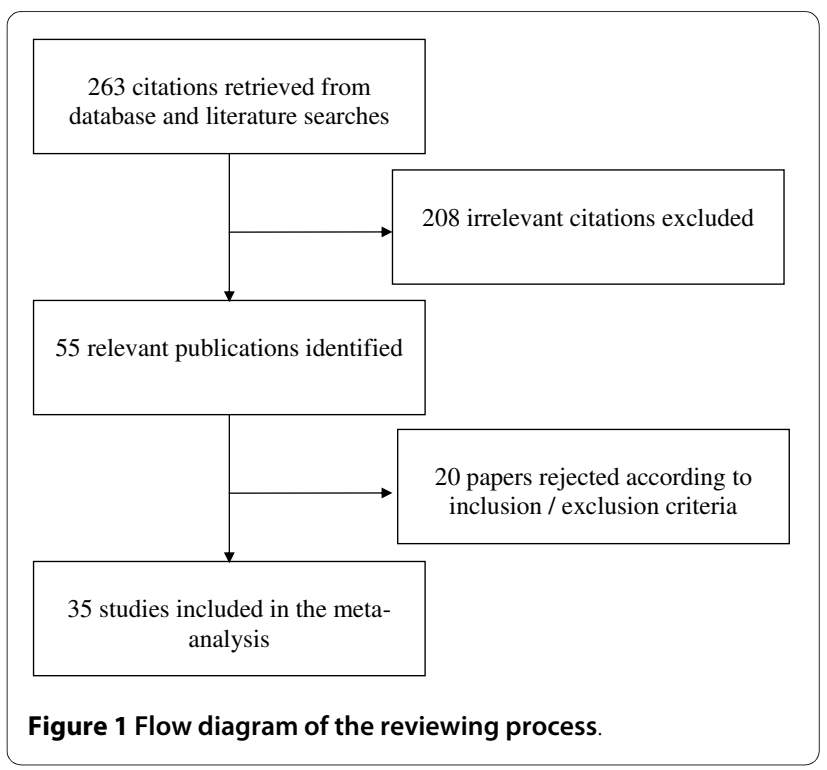


Table 1: Characteristics of included studies

\begin{tabular}{|c|c|c|c|c|c|c|c|c|c|c|c|c|}
\hline Authors & Year & Brand & Tesla & Patients (n) & Excluded (n) & Male (\%) & Mean Age (SD) & $\begin{array}{c}\text { Prevalence } \\
\text { (\% per patient) }\end{array}$ & $\begin{array}{c}\text { Coronary } \\
\text { Stenosis (\%) }\end{array}$ & Stressor* & Side Effects ${ }^{* *}(\mathbf{n})$ & Data assessment \\
\hline Al Saadi, (10) & 2000 & Philips & 1.5 & 40 & 6 & - & - & 100 & $\geq 75$ & D & 0 & 1/2 Quantitative \\
\hline Schwitter (11) & 2001 & GE & 1.5 & 48 & 1 & 83 & $59(-)$ & 79 & $\geq 50$ & $\mathrm{D}$ & 0 & 1/2 Quantitative \\
\hline Ibrahim, (12) & 2002 & Philips & 1.5 & 25 & 0 & 76 & $63(13)$ & 100 & $>75$ & A & - & 1/2 Quantitative \\
\hline Sensky (13) & 2002 & Siemens & 1.5 & 30 & 0 & 90 & $62(-)$ & 100 & $>50$ & A & 0 & Visual \\
\hline Chiu, (14) & 2003 & Siemens & 1.5 & 13 & 0 & 54 & $68(-)$ & 92 & $>50$ & A & 0 & Visual \\
\hline Doyle (15) & 2003 & Philips & 1.5 & 229 & 45 & 0 & $59(11)$ & 14 & $\geq 70$ & $\mathrm{D}$ & - & 1/2 Quantitative \\
\hline Ishida (16) & 2003 & GE & 1.5 & 104 & 0 & 78 & $66(12)$ & 74 & $>70$ & $\mathrm{D}$ & 0 & Visual \\
\hline Nagel (17) & 2003 & Philips & 1.5 & 90 & 6 & 81 & $63(8)$ & 51 & $\geq 75$ & A & 2 & 1/2 Quantitative \\
\hline Bunce (18) & 2004 & Picker & 1.5 & 35 & 0 & 77 & $56(12)$ & 49 & $\geq 50$ & A & 0 & 1/2 Quantitative \\
\hline Giang (19) & 2004 & GE & 1.5 & 94 & 14 & 69 & $58(-)$ & 65 & $\geq 50$ & A & 0 & 1/2 Quantitative \\
\hline Kawase (20) & 2004 & Philips & 1.5 & 50 & 0 & 58 & $66(12)$ & 66 & $\geq 70$ & $\mathrm{~N}$ & 0 & Visual \\
\hline Paetsch (21) & 2004 & Philips & 1.5 & 79 & 0 & 66 & $61(9)$ & 67 & $>50$ & $A$ & 0 & Visual \\
\hline Plein (22) & 2004 & Philips & 1.5 & 72 & 4 & 79 & $57(11)$ & 82 & $\geq 70$ & A & 1 & Visual \\
\hline Takase (23) & 2004 & GE & 1.5 & 102 & - & 83 & $66(9)$ & 74 & $>50$ & D & - & Visual \\
\hline Thiele (24) & 2004 & Philips & 1.5 & 20 & 0 & - & $64(8)$ & 90 & $\geq 70$ & A & 0 & 1/2 Quantitative \\
\hline Okuda (25) & 2005 & GE & 1.5 & 33 & 0 & 88 & $60(-)$ & 97 & $\geq 75$ & $\mathrm{D}$ & 0 & Visual \\
\hline Plein (26) & 2005 & Philips & 1.5 & 92 & 10 & 74 & $58(-)$ & 72 & $>70$ & A & 0 & 1/2 Quantitative \\
\hline Sakuma (27) & 2005 & Siemens & 1.5 & 40 & 0 & 70 & $65(9)$ & 52 & $>70$ & D & 0 & Visual \\
\hline Cury (28) & 2006 & GE & 1.5 & 47 & 1 & 81 & $63(5)$ & 65 & $\geq 70$ & $\mathrm{D}$ & - & Visual \\
\hline Klem (29) & 2006 & Siemens & 1.5 & 100 & 8 & 49 & $58(11)$ & 40 & $>50 / \geq 70$ & A & 1 & Visual \\
\hline Pilz (30) & 2006 & GE & 1.5 & 176 & 5 & 63 & $62(12)$ & 66 & $>70$ & A & 2 & Visual \\
\hline Rieber (31) & 2006 & Siemens & 1.5 & 50 & 7 & 88 & $61(8)$ & 67 & $>50$ & $A$ & 0 & 1/2 Quantitative \\
\hline Cheng (32) & 2007 & Siemens & $1.5 / 3$ & 65 & 4 & 75 & 64(8) & 66 & $\geq 50$ & A & 1 & Visual \\
\hline Costa (33) & 2007 & Siemens & 1.5 & 37 & 7 & 53 & $65(11)$ & 97 & $>50 />70$ & A & 0 & 1/2 Quantitative \\
\hline Greenwood (34) & 2007 & Philips & 1.5 & 35 & 0 & 89 & $55(-)$ & 83 & $\geq 70$ & A & 0 & Visual \\
\hline Kühl (35) & 2007 & Philips & 1.5 & 20 & 1 & 68 & $64(13)$ & 100 & $\geq 50$ & A & 0 & 1/2 Quantitative \\
\hline Merkle (36) & 2007 & Philips & 1.5 & 228 & 0 & 79 & $61(11)$ & 75 & $>50 />70$ & A & 0 & Visual \\
\hline Seeger (37) & 2007 & Siemens & 1.5 & 51 & 0 & 86 & $65(9)$ & 74 & $>70$ & A & 0 & 1/2 Quantitative \\
\hline Gebker (38) & 2008 & Philips & 3 & 101 & 3 & 70 & $62(8)$ & 69 & $\geq 50$ & A & 2 & Visual \\
\hline Meyer (39) & 2008 & Philips & 3 & 60 & 0 & 63 & $59(10)$ & 60 & $\geq 70$ & A & 0 & Visual \\
\hline Pilz (40) & 2008 & GE & 1.5 & 22 & 0 & 64 & $66(12)$ & 33 & $\geq 70$ & A & 0 & Visual \\
\hline Klein (41) & 2008 & Philips & 1.5 & 54 & 5 & 65 & $60(10)$ & 47 & $\geq 50$ & A & 2 & Visual \\
\hline Klem (42) & 2008 & Siemens & 1.5 & 147 & 11 & 0 & $63(11)$ & 27 & $\geq 70$ & A & 0 & Visual \\
\hline Thomas (43) & 2008 & Philips & 3 & 60 & 0 & 68 & - & 47 & $\geq 50$ & A & 0 & Visual \\
\hline Burgstahler (44) & 2008 & Philips & 1.5 & 23 & 3 & 65 & $68(12)$ & 40 & $\geq 70$ & A & 0 & Visual \\
\hline
\end{tabular}

* Stressor: A (Adenosine); D (Dypirydamole); N (Nicorandil) ${ }^{* *}$ n: significant side effects, which led to stop the MR exam. 
Table 2: Pooled summary results

\begin{tabular}{|c|c|c|c|c|c|c|c|}
\hline Studies & N studies & $\mathbf{N}$ & Sensitivity & Specificity & $\begin{array}{c}\text { Positive } \\
\text { Likelihood ratio }\end{array}$ & $\begin{array}{c}\text { Negative } \\
\text { likelihood ratio }\end{array}$ & $\begin{array}{c}\text { Diagnostic odds } \\
\text { ratio }\end{array}$ \\
\hline Per Patient analysis (all) & 26 & 2125 Patients & $89 \%(88-91)$ & $80 \%(78-83)$ & $4.18(3.31-5.27)$ & $0.15(0.11-0.20)$ & $33.65(22.09-51.27)$ \\
\hline Adenosine stressor & 20 & 1658 Patients & $90 \%(88-92)$ & $81 \%(78-84)$ & $4.47(3.39-5.88)$ & $0.14(0.11-0.18)$ & $37.17(25.16-54.91)$ \\
\hline Dipyridamole stressor & 5 & 417 Patients & $86 \%(80-90)$ & $77 \%(71-82)$ & $2.97(2.16-4.09)$ & $0.20(0.09-0.45)$ & $17.03(5.56-52.18)$ \\
\hline Visual assessment & 20 & 1624 Patients & $91 \%(89-93)$ & $79 \%(76-83)$ & $4.08(3.15-5.29)$ & $0.13(0.10-0.17)$ & $36.79(23.90-56.63)$ \\
\hline Semi-quant. assessment & 6 & 501 Patients & $82 \%(77-87)$ & $82 \%(77-86)$ & $4.88(2.62-9.09)$ & $0.22(0.13-0.37)$ & $25.44(8.90-72.70)$ \\
\hline Per Territory analysis & 17 & 2709 Territories & $82 \%(79-84)$ & $84 \%(82-85)$ & $4.90(3.66-6.55)$ & $0.23(0.20-0.27)$ & $23.23(18.33-29.45)$ \\
\hline \multicolumn{8}{|l|}{ Per Artery analysis } \\
\hline LAD & 8 & 662 Arteries & $83 \%(78-88)$ & $83 \%(79-86)$ & $4.37(2.96-6.44)$ & $0.22(0.16-0.31)$ & $21.42(10.94-41.94)$ \\
\hline$C X$ & 8 & 672 Arteries & $76 \%(70-82)$ & $87 \%(84-90)$ & $5.74(3.94-8.35)$ & $0.30(0.23-0.38)$ & $22.25(14.09-35.10)$ \\
\hline RCA & 8 & 657 Arteries & $78 \%(71-84)$ & $87 \%(83-90)$ & $5.58(3.74-8.32)$ & $0.29(0.21-0.38)$ & $23.07(14.55-36.57)$ \\
\hline
\end{tabular}

fied, 1,481 were males $(68.7 \%)$ and the mean age was 61.3 years.

\section{Diagnostic performance of stress perfusion CMR: Patient- based analysis}

Overall per-patient analysis results pooled from 26 studies (2,125 patients) demonstrated a sensitivity of $89 \%$ (95\% CI: $88-91 \%$ ), a specificity of $80 \%$ (95\% CI: $78-83 \%)$, a PLR of 4.18 (3.31-5.27), a NLR of 0.15 (95\% CI: 0.11-0.20), a DOR of 33.65 (95\% CI: 22.09-51.27), and an AUC of 0.92 (Figures 2, 3, 4, 5, 6). Statistical heterogeneity was observed for all relevant diagnostic performance measures. The per-patient prevalence of CAD was 57\% (1,205 of 2,125 patients).

With adenosine as the stressor (20 studies, 1,658 patients) the results were: a sensitivity of $90 \%$ (88-92\%), a specificity of $81 \%$ (78-84\%), a PLR of 4.47 (3.39-5.88), a NLR of 0.14 (0.11-0.18), a DOR of 37.17 (25.16-54.91), and an AUC of 0.93. Statistical heterogeneity was observed for all relevant diagnostic performance measures. With dipyridamole as the stressor (5 studies, 417 patients), the results were: a sensitivity of $86 \%$ (80-90\%), a specificity of $77 \%$ (71-82\%), a PLR of 2.97 (2.16-4.09), a NLR of 0.20 (0.09-0.45), a DOR of 17.03 (5.56-52.18), and an AUC of 0.84 . Statistical heterogeneity was observed for all relevant diagnostic performance measures, except specificity and positive likelihood ratio. ROC curves for stress perfusion CMR performed with adenosine or dipyridamole are shown in Figure 7.

A sensitivity analysis was carried out based on the equipment used (3 Tesla, and 1.5 Tesla MRI). For 3 Tesla (4 studies, 282 patients), results were: a sensitivity of $92 \%$ (87-95\%), a specificity of $78 \%$ (69-85\%), a PLR of 3.96 (2.78-5.63), a NLR of 0.12 (0.07-0.20), and a DOR of 35.74 (17.13-74.53). For 1.5 Tesla (23 studies, 1,904 patients), results were: a sensitivity $89 \%(87-91 \%)$, a specificity of $80 \%(78-83 \%)$, a PLR of 4.26 (3.26-5.55), a NLR of 0.15 (0.11-0.20), and a DOR of 34.25 (21.26-55.17).

\section{Diagnostic performance of stress perfusion CMR: Coronary territory and coronary artery-based analysis}

Per-territory results, pooled from 17 studies corresponding to 2,709 coronary territories, demonstrated a sensitivity of $82 \%(79-84 \%)$, a specificity of $84 \%(82-85 \%)$, a PLR of 4.90 (3.66-6.55), a NLR of 0.23 (0.20-0.27), and a DOR of 23.23 (18.33-29.45). At the territory level heterogeneity was significant for all relevant diagnostic performance measures except sensitivity, negative likelihood ratio and diagnostic odd ratios.

Per-artery analysis pooled 8 datasets and demonstrated for left anterior descending artery (LAD), circumflex artery $(\mathrm{CX})$ and right coronary artery (RCA), respectively, sensitivities of $83 \%, 76 \%$ and $78 \%$ and specificities of $83 \%, 87 \%$, and $87 \%$. Statistical heterogeneity was 
Table 3: Quality assessment (QUADAS)

\begin{tabular}{|c|c|c|c|c|c|c|c|c|c|c|c|c|c|c|}
\hline Study & Item 1 & em 2 & Item 3 & Item 4 & Item 5 & Item 6 & Item 7 & Item 8 & Item 9 & Item 10 & Item 11 & Item 12 & Item 13 & Item \\
\hline Al Saadi, 2000 (10) & no & yes & yes & unclear & yes & yes & yes & no & no & unclear & unclear & no & yes & yes \\
\hline Schwitter, 2001 (11) & $y=3$ & $y=0$ & $y \in s$ & $y=3$ & yes & $y=3$ & $y=0$ & $y=3$ & Yes & yes & $y=3$ & yes & yes & yes \\
\hline Ibrahim, 2002 (12) & yes & yes & yes & unclear & yes & yes & yes & yes & Yes & unclear & unclear & yes & yes & yes \\
\hline Sensky, 2002 (13) & yes & yes & yes & unclear & yes & yes & yes & yes & Yes & yes & yes & yes & yes & yes \\
\hline Chiu, 2003 (14) & yes & yes & yes & yes & yes & yes & yes & yes & Yes & yes & yes & yes & yes & yes \\
\hline Doyle, 2003 (15) & yes & yes & yes & unclear & yes & yes & yes & yes & Yes & no & no & yes & yes & yes \\
\hline Ishida,2003 (16) & yes & yes & yes & yes & yes & yes & yes & yes & Yes & yes & yes & yes & yes & yes \\
\hline Nagel, 2003 (17) & yes & yes & yes & yes & yes & yes & yes & yes & Yes & yes & yes & yes & yes & yes \\
\hline Bunce, 2004 (18) & yes & yes & yes & yes & yes & yes & yes & yes & Yes & yes & yes & yes & no & yes \\
\hline Giang, 2004 (19) & yes & yes & yes & yes & yes & yes & yes & yes & Yes & yes & yes & yes & yes & yes \\
\hline Kawase, $2004(20)$ & yes & yes & yes & yes & yes & yes & yes & yes & Yes & yes & yes & yes & yes & yes \\
\hline Paetsch, 2004 (21) & yes & yes & yes & unclear & yes & yes & yes & yes & Yes & yes & yes & yes & unclear & unclea \\
\hline Plein, 2004 (22) & yes & yes & yes & yes & yes & yes & yes & yes & Yes & yes & yes & yes & yes & yes \\
\hline Takase, 2004 (23) & yes & yes & yes & yes & yes & yes & yes & yes & Yes & yes & yes & yes & no & unclea \\
\hline Thiele,2004 (24) & yes & yes & yes & no & yes & yes & yes & yes & Yes & yes & yes & yes & yes & yes \\
\hline Okuda,2005 (25) & yes & yes & yes & yes & yes & yes & yes & yes & Yes & yes & yes & yes & yes & yes \\
\hline Plein, 2005 (26) & yes & yes & yes & yes & yes & yes & yes & yes & Yes & yes & yes & yes & yes & yes \\
\hline Sakuma,2005 (27) & yes & yes & yes & yes & yes & yes & yes & yes & Yes & yes & yes & yes & yes & yes \\
\hline Cury, 2006 (28) & yes & yes & yes & yes & yes & yes & yes & yes & Yes & yes & yes & yes & yes & yes \\
\hline Klem, 2006 (29) & yes & yes & yes & yes & yes & yes & yes & yes & Yes & yes & yes & yes & yes & yes \\
\hline Pliz, 2006 (30) & yes & yes & yes & unclear & yes & yes & yes & yes & . & yes & yes & yes & yes & yes \\
\hline Rieber, 2006 (31) & yes & yes & yes & yes & yes & yes & yes & yes & Yes & yes & yes & yes & yes & yes \\
\hline Cheng, 2007 (32) & yes & yes & yes & yes & yes & yes & yes & yes & Yes & yes & yes & yes & yes & yes \\
\hline Costa,2007 (33) & yes & yes & yes & yes & yes & yes & yes & yes & Tes & yes & yes & yes & yes & yes \\
\hline Greenwood, 2007 (34) & no & yes & yes & yes & yes & yes & yes & yes & Yes & yes & yes & yes & yes & yes \\
\hline Kuhl, 2007 (35) & yes & yes & yes & yes & yes & yes & yes & yes & Yes & yes & yes & yes & yes & yes \\
\hline Merkle, 2007 (36) & yes & yes & yes & yes & yes & yes & yes & yes & Yes & yes & yes & yes & yes & yes \\
\hline Seeger, 2007 (37) & yes & yes & yes & yes & yes & yes & yes & yes & Yes & yes & yes & yes & yes & yes \\
\hline Gebker, 2008 (38) & yes & yes & yes & yes & yes & yes & yes & yes & Yes & yes & yes & yes & yes & yes \\
\hline Meyer, 2008 (39) & yes & yes & yes & yes & yes & yes & yes & yes & Yes & yes & yes & yes & unclear & unclear \\
\hline Pilz, 2008 (40) & yes & yes & yes & yes & yes & yes & yes & yes & Yes & yes & yes & yes & yes & yes \\
\hline Klein,2008 (41) & yes & yes & yes & yes & yes & yes & yes & yes & Yes & yes & yes & yes & yes & yes \\
\hline Klem, 2008 (42) & no & yes & yes & yes & yes & yes & yes & yes & Yes & yes & yes & yes & yes & yes \\
\hline Thomas, 2008 (43) & yes & yes & yes & unclear & yes & yes & yes & yes & Yes & yes & yes & yes & yes & unclea \\
\hline Burgstahler,2008 (44) & yes & yes & yes & unclear & yes & yes & yes & yes & Yes & unclear & unclear & yes & yes & yes \\
\hline \multicolumn{15}{|c|}{$\begin{array}{l}\text { Item 1: was the spectrum of patients representative of the patients who will receive the test in practice?; Item 2: were selection criteria clearly } \\
\text { described?; Item 3: is the reference standard likely to correctly classify the target condition?; Item 4: is the time period between reference and } \\
\text { standard and index test short enough to be reasonably sure that the target condition did not change between the two tests?; Item 5: did the whole } \\
\text { sample or a random selection of the sample, receive verification using a reference standard of diagnosis?; Item 6: did patients receive the same } \\
\text { reference standard regardless of the index test results?; Item 7: was the reference standard independent of the index test (i.e. the index test did } \\
\text { not form part of the reference standard); Item 8: was the execution of the index test described in the sufficient detail to permit replication of the } \\
\text { test; Item 9: was the execution of the reference standard described in the sufficient detail to permit its replication?; Item 10: were the index test } \\
\text { results interpreted without knowledge of the results of the reference standard?; Item 11: were the reference standard results interpreted without } \\
\text { knowledge of the results of the index test?; Item 12: were the same clinical data available when test results were interpreted as would be available } \\
\text { when the test is used in practice?; Item 13: were uninterpretable/intermediate test results reported?; Item 14: were withdrawals from the study } \\
\text { explained. }\end{array}$} \\
\hline
\end{tabular}


observed for all the performance measurements except sensitivity and negative likelihood ratio for LAD and CX, and diagnostic odds ratio for CX.

\section{Discussion}

This meta-analysis showed stress perfusion CMR to have a high sensitivity (89\%) and a moderate specificity (80\%) at patient level for the diagnosis of significant obstructive CAD in patients with high prevalence of CAD (57\%). We included twelve more studies (on stress perfusion CMR) than the previous meta-analysis by Nandalur et al. [1], which showed a similar diagnostic performance with a pooled sensitivity and specificity of respectively $90 \%$ and $81 \%$ from 14 perfusion studies. A high false positive rate could have driven the relatively low specificity, and may be due to perfusion defects caused by: [1] dark rim artefacts, the hypo-intensities along the endocardial border of the left ventricular myocardium seen during first-pass transit of a MR contrast medium, thought to be due to a combination of the gadolinium bolus, motion and resolution [45]; [2] the presence of microvascular disease; and [3] spontaneous or therapeutic re-opening of a coronary artery supplying an area of myocardial infarction that has persistent microvascular obstruction $[28,32]$.

Alternatively, because CA detects luminal morphology rather than the functional significance of a stenosis, a false positive CMR results may in fact represent a 'false negative' angiogram in the context of angiographically 'invisible' small vessel disease capable of inducing subendocardial ischemia [40]. This potential source of error could be minimised if the hemodynamic significance of an epicardial coronary artery stenosis were to be determined by the measurement of the fractional flow reserve (FFR) during CA. If validated, this may represent a better reference standard than $\mathrm{CA}$ alone. However, although

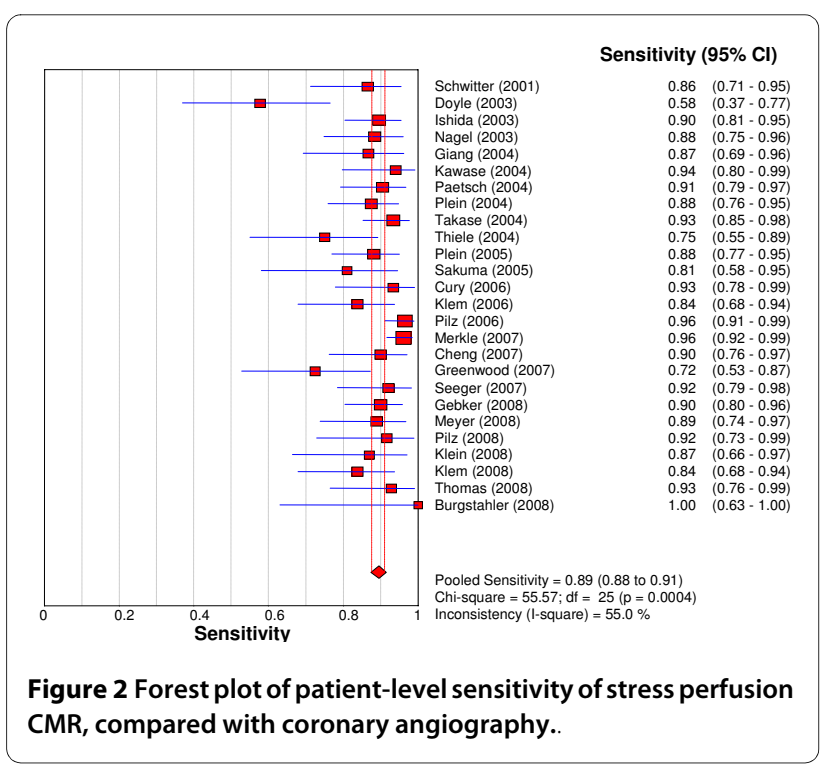

three studies found there to be a good correlation between the performance of stress perfusion CMR and CA with FFR measurement [31,33,35], sufficient data was not present to evaluate its accuracy in this study.

Another point to outline is that for some studies $[11,17,19]$, different decision thresholds to diagnose perfusion CMR as abnormal were appraised: for these studies, the reported sensitivity and specificity could be considered as optimistic because the end points was chosen retrospectively.

In addition, there was a large range of contrast doses used in the individual studies, with the dose of gadolinium administered in the included studies varying by 6fold, with dose ranging from 0.025 to $0.15 \mathrm{mmole} / \mathrm{kg}$. Although currently there is no consensus regarding the optimal dose and injection rates for perfusion CMR, two multicenter dose-ranging studies have evaluated the impact of contrast dose on the performance of perfusion CMR using a visual analysis [46,47]. In the first, Wolff et al. considered a low dose of $0.05 \mathrm{mmol} / \mathrm{kg}$ to be at least as efficacious as any higher dose, and hypothesized that higher doses preformed less well because of the increased likelihood and intensity of artefacts at these doses [46]. However, in the MR-Impact study, Schwitter et al. found better results were obtained using $0.1 \mathrm{mmol} / \mathrm{kg}$ [47].

In this meta-analysis, 18 studies were based on stress perfusion CMR alone [10-13,15,17,19-21,24,26,31$33,35,37,39,44]$, whilst the other 17 included a multicomponent examination (cine and/or late gadolinium enhancement (LGE) and/or coronary angiography and/or stress tagging) [14,16,18,22,23,25,27-30,34,36,38,40-43]. In their studies, Plein [22], Cury [28] and Klem [29] evaluated the differences in accuracy based on the sequences evaluated and found that all studies increased accuracy when using a combined analysis. In his study, Klem

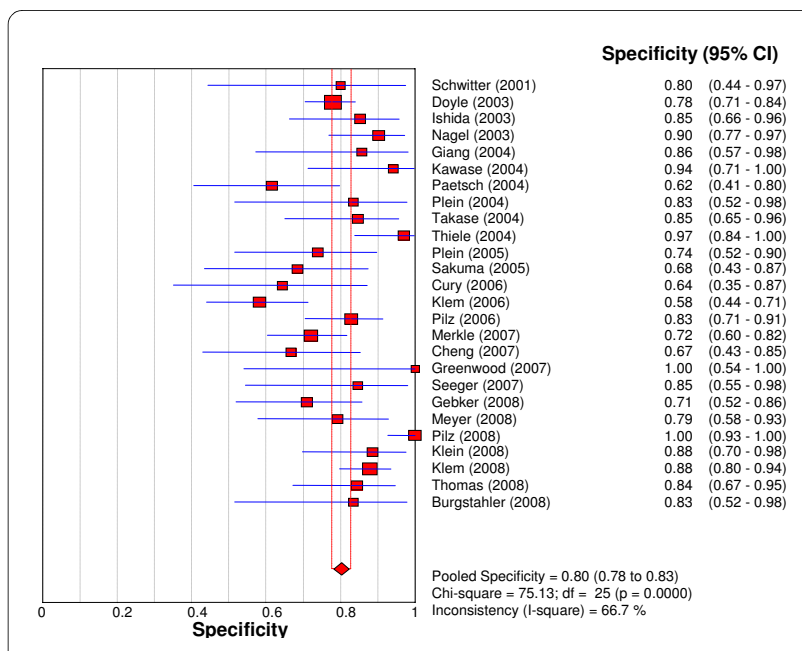

Figure 3 Forest plot of patient-level specificity of stress perfusion CMR, compared with coronary angiography. 


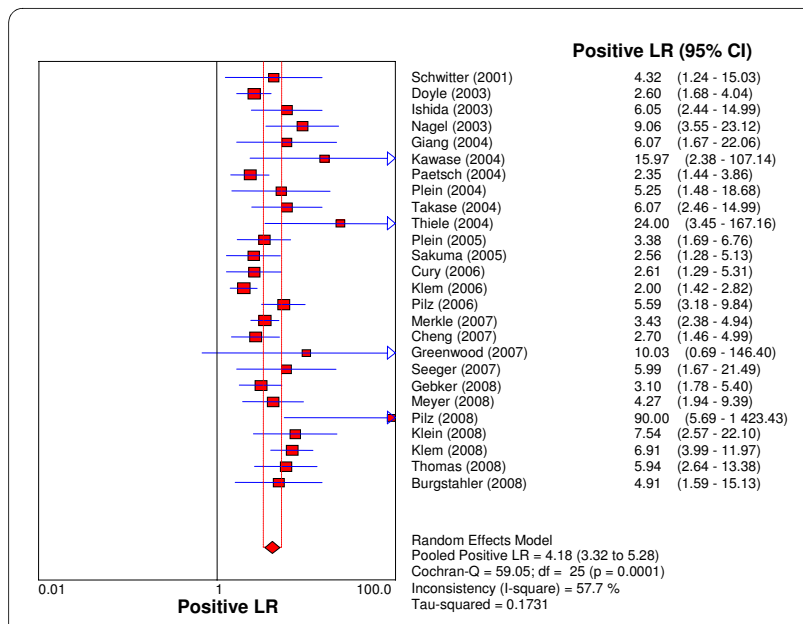

Figure 4 Forest plot of patient-level positive likelihood ratio of stress perfusion CMR, compared with coronary angiography.

reported increased specificity (moving from $58 \%$ to $87 \%$ ) when using an algorithm interpretation (including perfusion, cine and LGE).

Having access to data from different sequences (cine, perfusion, and LGE) is especially useful when one component shows a borderline result or is affected by image artefacts. Most of the authors have argued that rest perfusion is an important component because, in combination with late enhancement CMR, it can help distinguish true defects from artefacts on the stress perfusion images.

The fact that the meta-analysis demonstrated a low NLR for stress perfusion CMR suggests that a negative test result may in fact be more clinically useful. This is in keeping with several reports, in different clinical settings, of improved prognosis associated with a normal adenosine stress perfusion CMR scan [48-50]. This meta-analy-

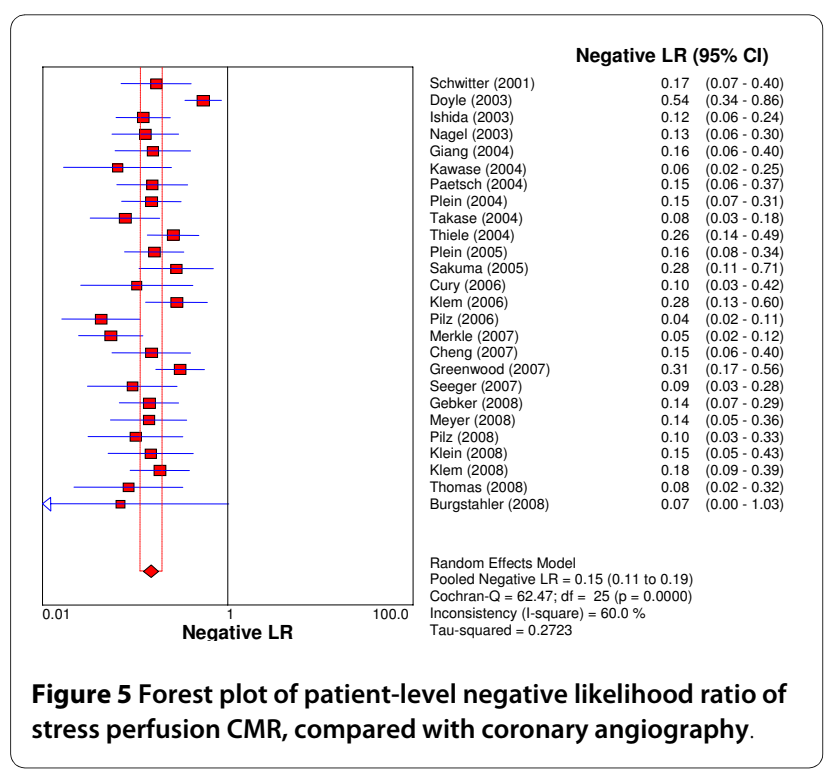

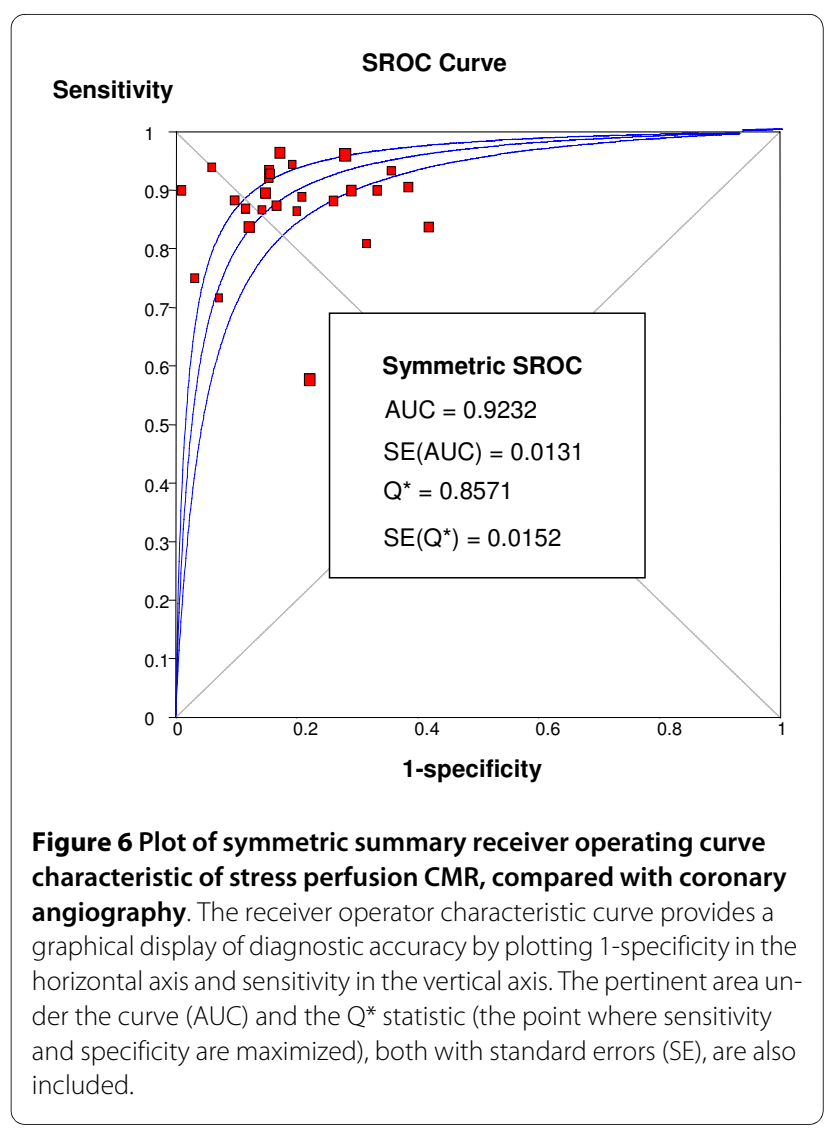

sis also demonstrated adenosine to be superior to dipyridamole as the vasodilating stressor agent. Adenosine may also be safer, with minor side effects of flushing and headache being reported to occur more frequently that any severe adverse effects [51]. Its shorter half life $(<$ $10 \mathrm{~s})$ is an added advantage. Moreover, adenosine has documented safety in the context of non-ST elevation acute coronary syndromes (in a study of 72 patients only one demonstrated intolerance), and in recent ST elevation myocardial infarction $[14,22,34]$.

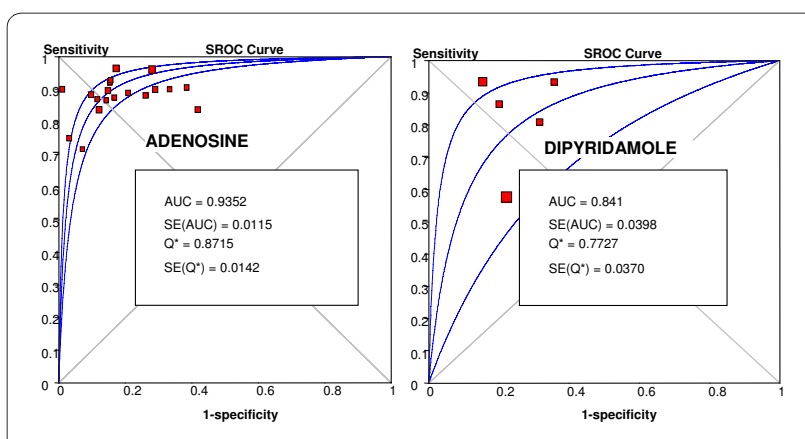

Figure 7 Plots of symmetric summary receiver operating curve characteristic of stress perfusion CMR, compared with coronary angiography for adenosine and dipyridamole stressors. 
From this analysis, visual assessment of stress perfusion CMR provided a higher sensitivity but a lower specificity than semi-quantitative assessment. Currently there is no consensus on the superiority of visual over semi-quantitative assessment, or on which method of semi-quantitative assessment should be used. However, the drawbacks of semi-quantitative assessment are that it is more timeconsuming, hence not ideal for day-to-day clinical purposes, and the lack of any homogeneous post-processing protocols. Therefore, visual assessment is currently the method most often used in routine clinical practice.

Only 4 studies were performed using 3T CMR, which provides improved resolution [32,38,39,43]. Enhanced sensitivity has been reported [32] and attributed to the higher signal-to-noise and contrast-to-noise ratios permitting improved detection of endocardial perfusion defects. Although most authors argue that the increased prevalence of dark rim artefacts at these higher field strengths (ranging from 8 up to $82 \%$ ) does not hamper myocardial perfusion analysis $[32,39,43]$, Gebker disagrees and suggests they could limit specificity by increasing false positive rates [38]. In this analysis, 3T CMR was also found to have a decreased specificity, indicating that higher false positive rates may be a real problem. Further studies will be necessary if this controversy is to be resolved.

The results of the per- territory-based analysis showed the anticipated decrease in sensitivity and increase in specificity seen when moving from the level of the patient to that of the coronary territory. Among the 8 studies that performed a coronary-artery level analysis, stress perfusion CMR had a higher sensitivity for detection of significant coronary disease in the LAD artery, compared with the CX and RCA. A possible explanation for this finding may have been the use of a surface radiofrequency coil, which led to lower signal intensities in the more distant inferior and lateral segments.

\section{Study limitations}

Although conventional $\mathrm{CA}$ is the established technique for diagnosing significant $\mathrm{CAD}$ in routine clinical practice, it remains an imperfect reference standard due to its inability to evaluate the hemodynamic significance of a stenosis.

Substantial inter-study heterogeneity in multiple performance characteristics were observed. Therefore, the pooled performance indices and their interpretation have to be treated with a degree of caution, even though the random-effects model used throughout the analysis should have compensated for this. The observed heterogeneity may have been due to variations in: (i) the image acquisition technique (MR scanner manufacturer, $1.5 \mathrm{~T}$ or $3 \mathrm{~T}$ field strengths, pulse sequence, number of slices, contrast dose and rate of infusion); (ii) the interpretation method (visual or semi-quantitative, post-processing techniques); (iii) the patient selection criteria (exclusion or inclusion of patients with prior myocardial infarction, patient populations with differing prevalence of CAD); and (iv) in the definition of significant obstructive CAD (50\% or $70 \%$ ). We noticed, as expected, that studies which performed analysis for $50 \%$ and for $70 \%$ coronary artery stenosis thresholds, reported an increased sensitivity and a decreased specificity when moving thresholds from $50 \%$ to $70 \%[29,33,36]$.

These general limitations of stress perfusion CMR could be addressed in future multi-centre studies if standardized imaging protocols, post-processing techniques and patient selection criteria are employed.

\section{Conclusion}

Stress Perfusion CMR has a high sensitivity and moderate specificity for the diagnosis of significant obstructive CAD compared with $\mathrm{CA}$ in patients with a high prevalence of the disease.

Future technical developments that increase spatial and temporal resolution whilst reducing artefacts may further improve the diagnostic performance of stress perfusion CMR, and in particular improve its specificity [32]. Currently, however, the low NLR makes stress perfusion CMR particularly accurate and useful in ruling out significant CAD.

\section{Competing interests \\ The authors declare that they have no competing interests.}

\section{Authors' contributions}

$\mathrm{MiH}$ conceived of the study, and participated in its design and coordination and drafted the manuscript. GF, MaH participated in its design and coordination and helped to draft the manuscript. GN, JE, helped to draft the manuscript. RM participated in the design of the study and performed the statistical analysis. All authors read and approved the final manuscript.

\section{Author Details}

'Department of Radiology, University Hospital of Caen, France, 2INSERM 919, Cyceron, Caen, France, ${ }^{3}$ Greyc Laboratory, CNRS UMR 6072, Caen, France, ${ }^{4}$ Department of Cardiology, University Hospital of Caen, France, 5 Department of Statistics, University Hospital of Caen, France and ${ }^{6}$ INSERM 744, Institut Pasteur de Lille, France

Received: 18 September 2009 Accepted: 19 May 2010

Published: 19 May 2010

\section{References}

1. Nandalur KR, Dwamena BA, Choudhri AF, Nandalur MR, Carlos RC: Diagnostic performance of stress cardiac magnetic resonance imaging in the detection of coronary artery disease. J Am Coll Cardiol 2007, 50:1343-53.

2. Whiting P, Rutjes AWS, Reitsma JB, Bossuyt PMM, Kleijnen J: The development of QUADAS: a tool for the quality assessment of studies of diagnostic accuracy included in systematic reviews. BMC Med Res Methodol 2003, 3:25

3. Glas AS, Lijmer JG, Prins MH, Bonsel GJ, Bossuyt PM: The diagnostic odds ratio: a single indicator of test performance. J Clin Epidemio 2003, 56:1129-1135

4. Devillé WL, Buntinx F, Bouter LM, Montori VM, de Vet HC, Windt DA van der, Bezemer PD: Conducting systematic reviews of diagnostic studies: didactic guidelines. BMC Med Res Methodol 2002, 2:9. 
5. Moses LE, Shapiro D, Littenberg B: Combining independent studies of a diagnostic test into a summary ROC curve: data-analytic approaches and some additional considerations. Stat Med 1993, 12:1293-1316.

6. Walter SD: Properties of the summary receiver operating characteristic (SROC) curve for diagnostic test data. Stat Med 2002, 21:1237-1256.

7. Lijmer JG, Bossuyt PM, Heisterkamp SH: Exploring sources of heterogeneity in systematic reviews of diagnostic tests. Stat Med 2002, 21:1525-1537

8. Zamora J, Muriel A, Abraira V: Meta-DiSc for Windows: A Software package for the Meta-analysis of Diagnostic Tests. XI Cochrane Colloquium. Barcelona 2003 [http://www.hrc.es/investigacion/ metadisc.html]

9. Halligan S, Altman DG: Evidence-based practice in radiology: step 3 and 4-appraise and apply systematic reviews and meta-analysis. Radiology 2007, 243:13-27.

10. Al-Saadi N, Nagel E, Gross M, Bornstedt A, Schnackenburg B, Klein C, Klimek W, Oswald H, Fleck E: Noninvasive detection of myocardial ischemia from perfusion reserve based on cardiovascular magnetic resonance. Circulation 2000, 101:1379-1383.

11. Schwitter J, Nanz D, Kneifel S, Bertschinger K, Büchi M, Knüsel PR, Marincek B, Lüscher TF, von Schulthess GK: Assessment of myocardial perfusion in coronary artery disease by magnetic resonance: a comparison with positron emission tomography and coronary angiography. Circulation 2001, 103:2230-2235

12. Ibrahim T, Nekolla SG, Schreiber K, Odaka K, Volz S, Mehilli J, Güthlin M, Delius W, Schwaiger M: Assessment of coronary flow reserve: comparison between contrast-enhanced magnetic resonance imaging and positron emission tomography. J Am Coll Cardiol 2002, 39:864-870.

13. Sensky PR, Samani NJ, Reek C, Cherryman GR: Magnetic resonance perfusion imaging in patients with coronary artery disease: a qualitative approach. Int J Cardiovasc Imaging 2002, 18:373-383.

14. Chiu CW, So NM, Lam WW, Chan KY, Sanderson JE: Combined first-pass perfusion and viability study at MR imaging in patients with non-ST segment-elevation acute coronary syndromes: feasibility study. Radiology 2003, 226:717-722.

15. Doyle M, Fuisz A, Kortright E, Biederman RW, Walsh EG, Martin ET, Tauxe L, Rogers WJ, Merz CN, Pepine C, Sharaf B, Pohost GM: The impact of myocardial flow reserve on the detection of coronary artery disease by perfusion imaging methods: an NHLBI WISE study. J Cardiovasc Magn Reson 2003, 5:475-485.

16. Ishida N, Sakuma H, Motoyasu M, Okinaka T, Isaka N, Nakano T, Takeda K Noninfarcted myocardium: correlation between dynamic first-pass contrast-enhanced myocardial MR imaging and quantitative coronary angiography. Radiology 2003, 229:209-216.

17. Nagel E, Klein C, Paetsch I, Hettwer S, Schnackenburg B, Wegscheider K, Fleck E: Magnetic resonance perfusion measurements for the noninvasive detection of coronary artery disease. Circulation 2003, 108:432-437.

18. Bunce NH, Reyes E, Keegan J, Bunce C, Davies SW, Lorenz CH, Pennell DJ: Combined coronary and perfusion cardiovascular magnetic resonance for the assessment of coronary artery stenosis. J Cardiovasc Magn Reson 2004, 6:527-539.

19. Giang TH, Nanz D, Coulden R, Friedrich M, Graves M, Al-Saadi N, Lüscher TF, von Schulthess GK, Schwitter J: Detection of coronary artery disease by magnetic resonance myocardial perfusion imaging with various contrast medium doses: first European multi-centre experience. Eur Heart J 2004, 25:1657-1665.

20. Kawase Y, Nishimoto M, Hato K, Okajima K, Yoshika J: Assessment of coronary artery disease with nicorandil stress magnetic resonance imaging. Osaka City Med 2004, 50:87-94

21. Paetsch I, Jahnke C, Wahl A, Gebker R, Neuss M, Fleck E, Nagel E: Comparison of dobutamine stress magnetic resonance, adenosine stress magnetic resonance, and adenosine stress magnetic resonance perfusion. Circulation 2004, 110:835-842.

22. Plein S, Greewood JP, Ridgway JP, Cranny G, Ball SG, Sivanathan MU: Assessment of non-ST-segment elevation acute coronary syndromes with cardiac magnetic resonance imaging. J Am Coll Cardiol 2004, 44:2173-2181

23. Takase B, Nagata M, Kihara T, Kameyawa A, Noya K, Matsui T, Ohsuzu F, Ishihara M, Kurita A: Whole-heart dipyridamole stress first-pass myocardial perfusion MRI for the detection of coronary artery disease. Jpn Heart J 2004, 45:475-486
24. Thiele H, Plein S, Breeuwer M, Ridgway JP, Higgins D, Thorley PJ, Schuler G, Sivananthan MU: Color-encoded semiautomatic analysis of multi-slice first-pass magnetic resonance perfusion: comparison to tetrofosmin single photon emission computed tomography perfusion and X-ray angiography. Int J Cardiovasc Imaging 2004, 20:371-384.

25. Okuda S, Tanimoto A, Satoh T, Hashimoto J, Shinmoto H, Higuchi N, Nozaki A, Kuribayashi S: Evaluation of ischemic heart disease on a 1.5 Tesla scanner: combined first-pass perfusion and viability study. Radiat Med 2005, 23:230-235.

26. Plein S, Radjenovic A, Ridgway JP, Barmby D, Greenwood JP, Ball SG, Sivananthan MU: Coronary artery disease: myocardial perfusion MR imaging with sensitivity encoding versus conventional angiography. Radiology 2005, 235:423-430.

27. Sakuma H, Suzawa N, Ichikawa Y, Makino K, Hirano T, Kitagawa K, Takeda $\mathrm{K}$ : Diagnostic accuracy of stress first-pass contrast-enhanced myocardial perfusion MRI compared with stress myocardial perfusion scintigraphy. AJR Am J Roentgenol 2005, 185:95-102.

28. Cury RC, Cattani CA, Gabure LA, Racy DJ, de Gois JM, Siebert U, Lima SS, Brady TJ: Diagnostic performance of stress perfusion and delayedenhancement MR imaging in patients with coronary artery disease. Radiology 2006, 240:39-45

29. Klem I, Heitner JF, Shah DJ, Sketch MH Jr, Behar V, Weinsaft J, Cawley P, Parker M, Elliott M, Judd RM, Kim RJ: Improved detection of coronary artery disease by stress perfusion cardiovascular magnetic resonance with the use of delayed enhancement infarction imaging. J Am Coll Cardiol 2006, 47:1630-1638.

30. Pilz G, Bernhardt P, Klos M, Ali E, Wild M, Hofling B: Clinical implication of adenosine-stress cardiac magnetic resonance imaging as potential gatekeeper prior to invasive examination in patients with AHA/ACC class II indication for coronary angiography. Clin Res Cardiol 2006, 95:531-538

31. Rieber J, Huber A, Erhard I, Mueller S, Schweyer M, Koenig A, Schiele TM, Theisen K, Siebert U, Schoenberg SO, Reiser M, Klauss V: Cardiac magnetic resonance perfusion imaging for the functional assessment of coronary artery disease: a comparison with coronary angiography and fractional flow reserve. Eur Heart J 2006, 27:1465-1471.

32. Cheng AS, Pegg TJ, Karamitsos TD, Searle N, Jerosch-Herold M, Choudhury RP, Banning AP, Neubauer S, Robson MD, Selvanayagam JB: Cardiovascular magnetic resonance perfusion imaging at 3-tesla for the detection of coronary artery disease: a comparison with 1.5-tesla. J Am Coll Cardiol 2007, 49:2440-2249.

33. Costa MA, Shoemaker S, Futamatsu H, Klassen C, Angiolillo DJ, Nguyen M, Siuciak A, Gilmore P, Zenni MM, Guzman L, Bass TA, Wilke N: Quantitative magnetic resonance perfusion imaging detects anatomic and physiologic coronary artery disease as measured by coronary angiography and fractional flow reserve. J Am Coll Cardio/ 2007, 50:514-522.

34. Greenwood JP, Younger JF, Ridgway JP, Sivananthan MU, Ball SG, Plein S Safety and diagnostic accuracy of stress cardiac magnetic resonance imaging vs exercise tolerance testing early after acute ST elevation myocardial infarction. Heart 2007, 93:1363-1368.

35. Kühl HP, Katoh M, Buhr C, Krombach GA, Hoffmann R, Rassaf T, Neizel M, Buecker A, Kelm M: Comparison of magnetic resonance perfusion imaging versus invasive fractional flow reserve for assessment of the hemodynamic significance of epicardial coronary artery stenosis. Am J Cardiol 2007, 99:1090-1095.

36. Merkle N, Wöhrle J, Grebe O, Nusser T, Kunze M, Kestler HA, Kochs M, Hombach V: Assessment of myocardial perfusion for detection of coronary artery stenoses by steady-state, free-precession magnetic resonance first-pass imaging. Heart 2007, 93:1381-1385.

37. Seeger A, Doesch C, Klumpp B, Kramer U, Fenchel M, Hoevelborn T, Gawaz M, Claussen CD, May AE, Miller S: MR stress perfusion for the detection of flow-limiting stenoses in symptomatic patients with known coronary artery disease and history of stent implantation. Rofo 2007, 179:1068-1073

38. Gebker R, Jahnke C, Paetsch I, Kelle S, Schnackenburg B, Fleck E, Nagel E: Diagnostic performance of myocardial perfusion MR at $3 \mathrm{~T}$ in patients with coronary artery disease. Radiology 2008, 247:57-63.

39. Meyer C, Strach K, Thomas D, Litt H, Nähle CP, Tiemann K, Schwenger U, Schild HH, Sommer T: High-resolution myocardial stress perfusion at $3 \mathrm{~T}$ in patients with suspected coronary artery disease. Eur Radiol 2008, 18:226-233. 
40. Pilz G, Klos M, Ali E, Hoefling B, Scheck R, Bernhardt P: Angiographic correlations of patients with small vessel disease diagnosed by adenosine-stress cardiac magnetic resonance imaging. J Cardiovasc Magn Reson 2008, 10:8.

41. Klein C, Gebker R, Kokocinski T, Dreysse S, Schnackenburg B, Fleck E, Nagel $\mathrm{E}$ : Combined magnetic resonance coronary artery imaging, myocardial perfusion and late gadolinium enhancement in patients with suspected coronary artery disease. J Cardiovasc Magn Reson 2008, 10:45.

42. Klem I, Greulich S, Heitner JF, Kim H, Vogelsberg H, Kispert EM, Ambati SR, Bruch C, Parker M, Judd RM, Kim RJ, Sechtem U: Value of cardiovascular magnetic resonance stress perfusion testing for the detection of coronary artery disease in women. J Am Coll Cardiol Img 2008, 1:436-45.

43. Thomas D, Strach K, Meyer C, Naehle CP, Schaare S, Wasmann S, Schild $\mathrm{HH}$, Sommer T: Combined myocardial stress perfusion imaging and myocardial stress tagging for detection of coronary artery disease at 3 Tesla. J Cardiovasc Magn Reson 2008, 10:59.

44. Burgstahler C, Kunze M, Gawaz MP, Rasche V, Wöhrle J, Hombach V, Merkle N: Adenosine stress first pass perfusion for the detection of coronary artery disease in patients with aortic stenosis: a feasibility study. Int J Cardiovasc Imaging 2008, 24:195-200.

45. Di Bella EVR, Parker DL, Sinusas AJ: On the dark rim artifact in dynamic contrast-enhanced MRI myocardial perfusion studies. Magn Reson Med 2005, 54:1295-1299.

46. Wolff SD, Schwitter J, Coulden R, Friedrich MG, Bluemke DA, Biederman RW, Martin ET, Lansky AJ, Kashanian F, Foo TK, Licato PE, Comeau CR: Myocardial first-pass perfusion magnetic resonance imaging: a multicenter dose-ranging study. Circulation 2004, 110:732-737.

47. Schwitter J, Wacker CM, van Rossum AC, Lombardi M, Al-Saadi N, Ahlstrom H, Dill T, Larsson HB, Flamm SD, Marquardt M, Johansson L: MRImpact: a comparison of perfusion-cardiac magnetic resonance with single-photon emission computed tomography for the detection of coronary artery disease in a multicentre, multivendor, randomized trial. Eur Heart J 2008, 29:480-489.

48. Ingkanisorn WP, Kwong RY, Bohme NS, Geller NL, Rhoads KL, Dyke CK, Paterson DI, Syed MA, Aletras AH, Arai AE: Prognosis of negative adenosine stress magnetic resonance in patients presenting to an emergency department with chest pain. J Am Coll Cardiol 2006, 47:1427-1432.

49. Jahnke C, Nagel E, Gebker R, Kokocinski T, Kelle S, Manka R, Fleck E, Paetsch I: Prognostic value of cardiac magnetic resonance stress tests. Adenosine stress perfusion and dobutamine stress wall motion imaging. Circulation 2007, 115:1769-1776.

50. Pilz G, Jeske A, Klos M, Ali E, Hoefling B, Scheck R, Bernhardt P: Prognostic value of normal adenosine-stress cardiac magnetic resonance imaging. Am J Cardiol 2008, 101:1408-1412.

51. Bernhardt P, Steffens M, Kleinertz K, Morell R, Budde R, Leischik R, Krämer $A$, Overhoff U, Strohm O: Safety of adenosine stress magnetic resonance imaging using a mobile cardiac magnetic resonance system. J Cardiovasc Magn Reson 2006, 8:475-478.

doi: $10.1186 / 1532-429 X-12-29$

Cite this article as: Hamon et al., Meta-analysis of the diagnostic performance of stress perfusion cardiovascular magnetic resonance for detection of coronary artery disease Journal of Cardiovascular Magnetic Resonance 2010, $12: 29$

\section{Submit your next manuscript to BioMed Central} and take full advantage of:

- Convenient online submission

- Thorough peer review

- No space constraints or color figure charges

- Immediate publication on acceptance

- Inclusion in PubMed, CAS, Scopus and Google Scholar

- Research which is freely available for redistribution

Submit your manuscript at www.biomedcentral.com/submit
C Biomed Central 